Notre Dame Law School

NDLScholarship

Natural Law Forum

$1-1-1958$

\title{
Human Purpose and Natural Law
}

Lon L. Fuller

Follow this and additional works at: http://scholarship.law.nd.edu/nd_naturallaw_forum

Part of the Law Commons

\section{Recommended Citation}

Fuller, Lon L., "Human Purpose and Natural Law" (1958). Natural Law Forum. Paper 28.

http://scholarship.law.nd.edu/nd_naturallaw_forum/28

This Article is brought to you for free and open access by NDLScholarship. It has been accepted for inclusion in Natural Law Forum by an authorized administrator of NDLScholarship. For more information, please contact lawdr@nd.edu. 


\section{HUMAN PURPOSE AND}

\section{NATURAL LAW*}

Lon L. Fuller

IT IS DIFFICULT to achieve effective communication in any discussion of a term that bears as many meanings as does "natural law." An adequate semantic analysis of this term would not only have to discriminate among such distinct meanings as can be discerned, but would also have to undertake something much more difficult, that is, to trace the complicated overlappings among these meanings that make them appear to have some sort of family resemblance. Such an analysis would not advance the purposes of this paper, for the problem I wish to present relates to a fundamental insight of ontology of the sort that may indeed be presupposed in the process of definition, but can scarcely be advanced by it.

It may help to avoid misunderstanding if I state briefly what I am not attempting to do in this paper. I am not, in any usual sense, advancing a "theory of natural law." I do not bring with me any code of nature. I do not hold myself open to deal with problems of casuistry, to say how "my concept of natural law" would solve this or that case. My concern is primarily to present a problem, and only incidentally and imperfectly to suggest a solution for it. The problem to which I address myself is one with which most theories of natural law attempt to deal, however clumsily. It is a problem that positivism commonly treats as simply nonexistent.

The problem $I$ have in mind is that which arises when we attempt to reconcile the now generally accepted dichotomy of fact and value with a purposive interpretation of human behavior. For it is my thesis that when we accept the full consequences that flow from a view which treats human action as goal-directed, the relation between fact and value assumes an aspect entirely different from that implied in the alleged "truism" that from what is nothing whatever follows as to what ought to be. Let me illustrate.

I see at a distance a boy who holds in his hand a small, gray, roundish object. He seems to be contemplating this object intently. After a period of hesitation, he places the object carefully between his palms and repeatedly presses on it. He then relaxes his grip, holds the object loosely in his left hand, and begins to look about him on the ground. He apparently finds

- Professor Fuller's article originally appeared at 53 Journal of Philosophy 697 (1956). It is reprinted here by permission of the editors. 
what he wants, for he bends over and picks up a stick. This he uses for a while to prod or push against the object. He then throws the stick away and bends to strike the object several times against a rock. Shortly he gives up this activity and walks about as if undecided what to do next. Suddenly he begins to gather sticks together, arranges them on the ground in a pile, lights a match to them, places the object in the fire, and then stands off in an attitude of expectancy.

Now it is obvious that something happens to this account, a sudden accretion of meaning occurs, when we learn that the boy was throughout trying to open a clam. Without this clue I could not interpret what I observed, retain accurately in memory the shape of the events that occurred, or give to another a really coherent account of what happened.

A former age would have said quite simply that this clue of purpose was necessary to "understand" what was happening. Let us, however, define "understanding" in terms consonant with modern conceptions of scientific method; that is, let us consider that we have "understanding" when we are able to control and predict events. It is obvious that any chance I might have of redirecting the boy's actions, by diverting him into a new line of activity, would depend in large measure on my knowing what he was trying to do. In a similar manner, if at any stage $I$ was able to predict what he would do next - for example, if I had guessed correctly what he would do after he had gathered the sticks together - it would be because I had discerned, in general terms at least, the purpose he was pursuing.

Now it can be demonstrated, I believe, that in any interpretation of events which treats what is observed as purposive, fact and value merge. In such a case the view that value is something foreign to a purely factual account - something projected by the observer on the thing observed simply will not stand scrutiny. If I can predict that the boy's attempt to open the clam by pressing it between his hands will soon be given up, it is because I know that this is not a "good" way to open clams; judged in the light of the boy's purpose it lacks "value." Here the structure of the events as they unroll - the reality of what happens through time - contains an element of value, so that we can say: "This is bad, it will not last," or "This is good, we may expect it to continue."

It will be objected at this point, I am sure, that this whole demonstration rests on the most transparent of fallacies. It will be said that a "value" element is no more intrinsic to the facts I have recounted than it would be, let us say, if $I$ were to observe a five-foot ladder leaning against a fifteen-foot wall. Certainly this state of affairs, as related, suggests nothing like a value 
judgment, yet I can say of it, "This is bad," if I assume that someone of normal stature plans to use the ladder to scale the wall, and if I provisionally accept his purpose as a valid one. The only difference between this case and my previous illustration, it will be said, is that as we watch the boy with the clam, the observation of the physical events, the perception of the boy's purpose, and our provisional acceptance of that purpose as a standard for valuing what occurs, all proceed contemporaneously, so that what is in principle distinct is here blended, thus creating an illusion that fact and value have somehow merged. That they remain distinct even when we are observing the results of purposive action is made clear by the illustration of the ladder and the wall.

This argument ignores the fact that when we are dealing with purposive action projected through time, the structure that we observe, recall, and report lies, not in any instantaneous state of affairs, but in a course of happening, which can be understood only if we participate in a process of evaluation by which the bad is rejected and the good retained. If I look over the shoulder of a mathematician working on a problem beyond my comprehension, I cannot predict or control what he will do, nor will I be able to give more than a trivial account of what $I$ have observed. In such a case, as in that of the boy and the clam, the "fact" of the event can be understood only by one sufficiently capable of evaluation to know what is happening when a good thing is embraced or a bad one rejected. If any of my illustrations produces an "illusion" it is that of the ladder leaning against the wall, where an interruption in purposive action leaves a deposit in the form of a temporary collocation of physical objects we can talk about without importing into it any greater purposive element than is intrinsic to all language.

At this point it will be argued, I am sure, that my observations confuse the question of ultimate value with that of selecting the most effective means for realizing an immediate purpose. It may be true, it will be said, that to understand and describe purposive action we have to participate vicariously in an act of valuation, but any such valuation is necessarily relative to what Dewey called the "end-in-view." That there are good and bad ways of opening clams leaves untouched the question whether opening clams is itself an activity entitled to be called good.

But is it true that a course of purposive action can be understood simply by perceiving at any given moment of time whatever immediate purpose is then being pursued? Shall we treat the shift from one purpose to another as a kind of miracle, neither requiring nor permitting any participation by the observer in the evaluation that produced the shift? 
In my now sadly overworked molluscoidal illustration I described a case where a series of apparently discrete acts were directed toward what I called a single purpose. Actually it would have been better, even in that simple case, to speak, not of a purpose, but of a congeries of related purposes. "Opening a clam" by pressing on it is obviously something different from the "opening" that might result from prying. But suppose a still greater shift in the direction of the boy's activities. He is told, for example, that there is an aquarium nearby where he can observe clams feeding and digging in the sand as they would in their native habitat. He drops his clam and runs to look at the aquarium. Shall we say that there has now been a complete break in the continuity of his actions, or shall we say that he has merely hit on a better means of satisfying what was his true purpose throughout? Other shifts in the boy's activities might be imagined, such as putting down the clam and turning to an encyclopedia, where before reaching the C's he becomes entranced with an article on astronomy. The essential point I am trying to convey is that to understand a course of action of any complexity a single "purpose" does not suffice. If I understand what the boy is doing it is because of our shared human nature, a nature that in both of us is at all times incomplete and in process of development.

Any single human purpose - whether expressed in actions or words is an incomplete thing when severed from the total system of which it forms a part. The meaning of any given purpose is always controlled by latent purposes in interaction with it. This is beautifully illustrated in an example of Wittgenstein's:

Someone says to me: "Show the children a game." I teach them gaming with dice, and the other says, "I didn't mean that sort of game." Must the exclusion of the game with dice have come before his mind when he gave me the order?1

Those who claim large powers to ascribe to words or human actions a meaning innocent of evaluation will do well to ponder this example.

The dilemma we confront when we attempt to apply the fact-value dichotomy to human purpose may be restated in terms of the means-end relation. To anyone who reflects on moral issues two lines of thought will open up with respect to means and ends, each carrying with it the quality of self-evidence. On the one hand, it seems clear that the selection of an apt means for the realization of a given end is an activity engaging man's reasoning faculties and his capacity for accurate analysis and observation. The

1. Philosophical Investigations 33 (1953). 
other line of thought leads, with equal persuasiveness, to the conclusion that this activity must have a terminal point and that the end ultimately pursued cannot be determined by analysis or observation, but must in some manner or other be projected upon events. These two lines of thought can coexist peacefully so long as they are not applied to any process of decision. When that happens the distinction that holds them apart disappears and their latent conflict becomes manifest. For when we are confronted with the necessity of making an actual decision about a course of action, means and ends no longer arrange themselves in tandem fashion, but move in circles of interaction.

We are thus faced with a dilemma like that presented by the wave and corpuscular theories of light in physics - two views, each of which seems valid when taken in isolation, prove impossible to combine. In ethics, unfortunately, this conflict manifests itself precisely at the only point where theory makes any difference in human affairs.

I do not pretend to be able to remove the difficulties presented by this problem. I suggest that part of the trouble lies with language. The forms of language, particularly those operating with subject, verb, and predicate, are well suited to describe action unilaterally projected, but are an awkward instrument for dealing with interaction. The words we use to describe mental activity may also confuse the issue. The term "reasoning" seems apt when applied to the process of selecting the most effective means for realizing an accepted end, but inappropriate for describing the process by which, through reflection and contemplation, we make up our minds "what we really want," though in practice the two processes go forward in interaction and both engage the higher nervous centers.

No doubt the true source of the difficulty lies deeper. The means-end problem is simply an outcropping of the deeper mystery of life itself. Living matter is distinguished by the fact that it combines two qualities that do not appear together in inanimate matter: directiveness and adaptability. In the obscure interaction of these two qualities lies the source of our difficulties with the means-end problem. Perhaps the mystery that attaches to the formation of ends is only a particular expression of that which surrounds all biological phenomena which seem to project themselves from within the organism. We see no cause for wonder when an animal takes cover to escape the cold, but feel we have witnessed a near-miracle when another animal responds to the same stimulus by growing longer hair - though we would be hard put to it to explain why the one phenomenon seems so commonplace, the other so mysterious. Perhaps in the case of the animal that grows 
a thicker coat to meet the winter our difficulty arises from the fact that the familiar means-end relationship seems lacking, so that an end appears to realize itself directly. Our minds feel comfortable, in other words, when we are dealing with the means-end relation, but become uneasy when we attempt to understand the members of this relationship in isolation from one another.

If these meager suggestions have any value at all it will be in helping to identify the problem, not in providing a solution for it. Indeed, I believe the issue we now confront is not that of solving the problems, but of deciding how we should comport ourselves in the absence of a solution.

One answer to this predicament is by now thoroughly familiar. In its most extreme form it runs somewhat as follows: The validity of human ends and "values" is not a matter for reasoned demonstration. While the selection of an apt means has the quality of an intellectual undertaking, a means without an end is a monstrosity. Until we have selected an end by some fiat of the will, any discussion of means is therefore futile. Every means-end problem is unique. If it were not, this would imply that the formation of ends is itself a lawful process, subject to rational cognition, which, it is assumed, cannot be the case.

From the same human predicament, an opposing school of thought extracts the opposite conclusion. Since in the process of decision means and ends interact, it is impossible to assign in advance precise limits to the role of reason. Let us therefore push our understanding as far as it will take us into the obscure area where means and ends interact; let us seek collectively to discover as much agreement in this area as the nature of the case permits.

This view asserts the reality of a process that may be called the collaborative articulation of shared purposes. Through the centuries it has been in spite of all of its extravagances and dogmatisms - the school of natural law that has kept alive faith in that process. Is the faith justified?

I believe we have much evidence that it is. In the affairs of daily life, we all know from personal experience that in moments of crisis consultation with a friend will often help us to understand what we really want. It does not make much difference whether our adviser tells us, in effect, "Look carefully to your means," or "Consider carefully your end." The effect of the advice is in either case to initiate a process of reflection and consultation that may change our whole understanding of ourselves. The rapport needed to make such a consultation profitable is obviously difficult to achieve, and it may seem, therefore, that collaboration on such a personal level is without relevance to the larger issues of law and ethics. 
Yet I think that in the history of the common law we have an example which teaches how a social institution may derive its integrity and vitality from the same spirit of consultation as that which animates the discussion of two friends sharing a problem together. The common law is not the work of any one judge, but of many, collaborating through time. In the course of its history the implementation of its rules has been improved and refined. At the same time, the rules themselves have often been revised to make possible an effective implementation of them. Though the common law is said to be built on precedent, there is no controlling verbal formulation of the meaning of any particular precedent. What the court said in a former case is always subject to reinterpretation as new situations arise. The scope of the precedent is determined not only in the light of the end-in-view pursued by the court that decided it, but in the light of ends then out of view because not stirred into active consciousness by the facts of the case being decided. The problem posed by Wittgenstein's example of the children's game is so familiar to the common law as hardly to seem novel at all. And, except for occasional lapses into literalism, its response has always been, "No, he did not mean that kind of game."

What I have called the collaborative articulation of shared purposes is also illustrated, I believe, on a much homelier plane, familiar to everyone. I refer to the problem of giving an adequate definition for everyday words. In modern discussions of semantics it is a commonplace to assert that the lexicographer is merely an observer and recorder of usage. This is nonsense. We all know that developing a good definition for a familiar word is hard intellectual labor. If one will take a common word like "stove" or "money" and compare his own offhand definition with that given in a good dictionary, he may learn, to be sure, that usages exist which he overlooked or which were unfamiliar to him. But what he will chiefly discover is how miserably his own definition failed to articulate clearly the purposive core of the word, which he "knew" as well as anyone, but was unable on short notice to bring to adequate formulation. A good lexicographer not only knows more about usage than you and I, but his skill in analysis may enable him to predict, more successfully than we could, how we ourselves use the word in contexts we have not yet confronted.

The modern rejection of any notion that men may by pooling their intellectual resources come to understand better what their true purposes are is revealed in the scorn that generally greets essays carrying such titles as, "What is Art?" Of course much that is pretentious and empty appears under such titles, but the modern rejection does not rest on the quality of the offer- 
ings, being grounded rather on principle. It is said that any such title invites a confusion of fact and value and serves generally as a cover for a fraudulent intent to pass off the subjective opinion of the author about what art ought to be for a description of what it is in fact - as if it were possible to describe a major area of human striving without participation in that striving and as if that participation could be otherwise than creative! If the objection is more radically phrased so that it could not be removed by changing the title to read, "What I Think Art Ought to Be," then what is really being rejected is the reality of what I have called the collaborative articulation of shared purposes.

That rejection makes itself most tragically felt today, I believe, in our failure to carry on the work of former generations in analyzing and discussing what may be called the forms of social order. I use that term broadly to include rules, procedures, and institutions - all the ways, in short, in which the relations of human beings to one another are subjected to a formal ordering, whether by consent, habit, or command. As I use the term it cuts across law, politics, economics, sociology and ethics, and even includes systems of play. Thus, contract, adjudication, the majority principle, and the threestrike, four-ball rule are all forms of social order.

These forms are generally viewed only in their most obvious aspect, that is, as means to the realization of human ends. But they are also themselves ends, in two closely related senses. They are ends in the sense that, although we make them, they help to make us what we are, man's dependence on society being what it is. Any particular economic system not only serves to satisfy antecedent wants, but also generates its own peculiar pattern of human wants. Secondly, any form of social order contains, as it were, its own internal morality. Thus, we may judge football by an external standard and say, "Football is a good game," but we may also judge it by standards drawn from its own internal requirements and say, "Football will become impossible if this sort of thing is allowed to go on." We may appraise adjudication as a means of settling disputes and compare it with alternative methods of accomplishing the same object. We may also analyze its intrinsic demands and recognize that any attempt to combine the functions of judge and mediator represents a dangerous undertaking. Finally, we may agree with Proverbs that, "The lot causeth contentions to cease, and parteth between the mighty," though we may regret that the wisdom of Solomon was not applied to define more precisely for us the kinds of contentions that are most suited for disposition by a casting of lots. At the same time, deliberate resort to chance as a form of social order makes its own technical demands if it is to be in 
fact what it purports to be.

These remarks may be taken to indicate an interest in practical problems of economics, law, and politics, rather than any concern for ethical theory. I believe, however, that the forms of social order cast their shadows across ethical discussions which contain no explicit reference to them. Thus we find the ideal of voluntary settlement (contract), or the informed judgment of a disinterested third party (adjudication), or the majority principle serving as tacit premises in discussions that seem remote from anything like the technical problems of social organization.

The issues $I$ have tried to suggest in these concluding remarks range from the most trivial to the most crucial that human beings can face. These issues were once in active discussion and dispute. We are still living with the resolutions former generations found for them. It is difficult to see how the interrupted work of these generations can be resumed until we have reacquired some measure of sympathy for the essential aims of the school of natural law. 